\title{
Inhibition of photosynthesis in cucumber leaves by oxybenzone
}

\author{
X. ZHONG ${ }^{*, * *}$, Y.T. LI ${ }^{*, * * *}$, Z.S. ZHANG ${ }^{*, * * *}$, S.H. LI $^{* *}$, Y.M. LI" ${ }^{* *}$ B.B. LIU*, Q.M. LI ${ }^{*, * *,+}$, \\ and H.Y. GAO, \\ State Key Laboratory of Crop Biology, Shandong Agricultural University, 271018 Tai'an, China* \\ College of Horticulture Science and Engineering, Shandong Agricultural University, 271018 Tai'an, China** \\ College of Life Sciences, Shandong Agricultural University, 271018 Tai'an, China***
}

\begin{abstract}
Oxybenzone (OBZ), a widely used sunscreen additive, has damaging effects on corals and plants. This study demonstrated that OBZ significantly inhibited photosynthesis and growth of cucumber (Cucumis sativus L.) seedlings. Combined analyses of chlorophyll fluorescence and 820-nm reflection suggested that OBZ severely inhibited photosynthetic electron transport (PET) from $\mathrm{Q}_{\mathrm{A}}$ to cytochrome $b_{6} f\left(\mathrm{Cyt} b_{6} f\right)$ complex, restricting the reduction of the reaction center in PSI. Separate measurements of PSI and PSII PET in chloroplasts indicated that OBZ inhibited the PET of neither PSII nor PSI, but it severely inhibited the whole linear PET. We thus confirmed that the inhibition of PET by OBZ was due to the inhibition of plastoquinones (PQs) and/or the Cyt $b_{6} f$ complex between PSI and PSII. PET is essential for producing ATP and NADPH used in $\mathrm{CO}_{2}$ assimilation. Therefore, limiting the use of sunscreens containing OBZ is significant in protection of aquatic and terrestrial ecosystems and ensuring the safety of agricultural production.
\end{abstract}

Additional key words: carboxylation efficiency; fluorescence transient; gas exchange; JIP-test.

\section{Introduction}

Oxybenzone (OBZ), a popular additive in sunscreen, can protect human skin by blocking ultraviolet (UV) rays from the sun (Baker et al. 2015). In addition to being used in sunscreens, OBZ is also widely used in perfumes, shampoos, lip balms, and other pharmaceuticals and personal care products (PPCPs) (Aguirre et al. 1992, Emonet et al. 2001, Kasichayanula et al. 2007). OBZ can enter rivers, lakes, groundwater, sewage, and so on through human activities and was identified as an 'emerging environmental pollutant' by the Environmental Protection Agency of the USA (Rodil et al. 2012, Agüera et al. 2013). With the rise in coastal tourism, a large number of coral reefs in coastal areas are being exposed to water containing OBZ (Barón et al. 2013, Tashiro and Kameda 2013). OBZ, as a pseudo-persistent pollutant, has a longterm toxic effect on the environment (Vione et al. 2013).

Downs et al. (2016) observed that OBZ damaged symbiotic algae and lead to death of coral. This compound also causes photobleaching of corals and damage of aquatic ecosystem (Downs et al. 2016). Mao et al. (2017) showed that algae could absorb OBZ in culture solution, resulting in a decrease in chlorophyll $(\mathrm{Chl})$ content and the inhibition of growth. Recently, the toxic effects of OBZ on organisms have attracted attention. Many coastal regions have begun to prohibit the use of sun creams that contain OBZ and other harmful chemicals (e.g., Hawaii in the USA, marine ecoparks in Mexico, and the Pacific nation of Palau). The media has frequently called on swimmers to reduce the use of body creams containing OBZ. However, many skin experts as well as many sun cream manufactures claim that this policy lacks supporting academic evidence from third parties. Other factors may lead to coral poisoning. To date, most research on OBZ has mainly emphasized animals and humans (Aguirre et al. 1992, Lenique et al. 1992, Emonet et al. 2001, Kasichayanula et al. 2007), whereas a few studies on plants have mainly focused on the absorption of OBZ, transformation of OBZ, and resulting changes in the antioxidant system (Chen et al. 2017, 2018).

Photosynthesis is one of the most important pathways in plants. More than $90 \%$ of a plant's dry matter is derived from photosynthesis. If OBZ can inhibit plant photosynthesis, then almost all plants, including algae and lower and higher plants, can be damaged by OBZ. Our recent study showed that OBZ immediately inhibited photosynthetic electron transport (PET) in chloroplasts of cucumber plants, resulting in the overproduction of reactive oxygen species (ROS) (Zhong et al. 2019a).

However, the mechanisms of inhibiting photosynthesis by OBZ is still unknown. Furthermore, our previous study used detached leaves, and whether OBZ can damage higher

Received 19 April 2019, accepted 2 October 2019.

${ }^{+}$Corresponding author; e-mail: gslqm@sdau.edu.cn

Abbreviations: $\mathrm{CE}$ - carboxylation efficiency; $\mathrm{Chl}$ - chlorophyll; $C_{\mathrm{i}}$ - intercellular $\mathrm{CO}_{2}$ concentration; Cyt $b_{6} f-$ cytochrome $b_{6} f$; DCMU - 3-(3,4-dichlorophenyl)-1,1-dimethyl-urea; DCPIP - 2,6-dichlorophenolindophenol; $g_{\mathrm{s}}$ - stomatal conductance; MV methylviologen; OBZ - oxybenzone; OJIP curve - the chlorophyll $a$ fluorescence transient; $p$-BQ - p-benzoquinone; PEA - plant efficiency analyzer; PET - photosynthetic electron transport; $P_{\mathrm{N}}-$ net photosynthetic rate; PPCPs - pharmaceuticals and personal care products; $\mathrm{PQ}$ - plastoquinone; ROS - reactive oxygen species; RuBP - ribulose-1,5-bisphosphate; $\mathrm{V}_{\mathrm{J}}$ - variable fluorescence at 'J' point. Acknowledgments: We thank the National Natural Science Foundation of China (31872154, 31701966, and 31771691). 
plants via their roots remains unresolved. Moreover, the degree to which OBZ can harm cultivated plants is unclear. By investigating the effects of different OBZ contents on the growth, Chl content, Chl fluorescence transient and PET of PSI, PSII, and whole linear electron transport of the cucumber leaves, we aimed to answer these questions. Answering these questions could help us further understand the negative effect of OBZ on plants and its mechanism and provide further evidence to avoid the use of sunscreen or PPCPs containing OBZ in order to protect the environment and maintain the balance of marine and terrestrial ecosystems.

\section{Materials and methods}

Plant materials: A cucumber (Cucumis sativus L.) cultivar 'Jinyou-35' was used as the experimental material. The research was done in Tai'an, China. The plant seedlings were cultured in pots filled with culture substrate. Sufficient water and nutrients were supplied throughout the growth period. The growing conditions were the same as that described in our previous research (Zhong et al. 2019b). The cucumber seedlings were irrigated with nutrient solution containing different $\mathrm{OBZ}$ contents $(0,2.28,22.8$, and $45.6 \mathrm{mg} \mathrm{L}^{-1}$ ) every morning. To rinse off the OBZ accumulated the day before, the seedlings were watered with the nutrient solution, the volume of which was twice the maximum water content of the soil to ensure that the OBZ content was the same throughout the growing period.

OBZ suspensions: The OBZ was bought from Sigma Aldrich Company. The preparation and preservation of OBZ suspensions were performed according to Zhong et al. (2019a). The OBZ solids were first dissolved in a small amount of alcohol $(0.5 \mathrm{~mL})$ and then put into the Hoagland nutrient solution or reaction agents to make the suspensions with different contents used in this experiment. Hoagland nutrient solutions or reaction agents without OBZ were used as control treatments. The control solution and reaction agent were prepared in exactly the same way as the other OBZ suspensions, except without OBZ.

Plant growth: The height, leaf area, stem diameter, and Chl content of the cucumber seedlings were measured after the seedlings were treated with different OBZ contents for $15 \mathrm{~d}$. The main stem height was measured as a plant height. The stem diameter, at $1 \mathrm{~cm}$ above the base, was measured using a micrometer. The leaf area was measured using a CI-202 leaf area meter (CID Bio-Science Inc., Washington, USA). The Chl content was measured according to Porra (2002). Leaf chlorophyll was extracted with $80 \%$ acetone in the dark for $72 \mathrm{~h}$ at room temperature. The extracts were analyzed using UV-visible spectrophotometer UV-1601 (Shimadzu, Japan) to measure the OD values at 663 and $645 \mathrm{~nm}$.

Gas exchange: After $15 \mathrm{~d}$ of OBZ treatment, the measurement of gas exchange was performed using a CIRAS-3 photosynthesis system (PP-Systems, Hitchin, USA) under ambient $\mathrm{CO}_{2}$ concentration $\left(400 \mu \mathrm{mol} \mathrm{mol}^{-1}\right)$, saturated light intensity $\left[1,000 \mu \mathrm{mol}\right.$ (photon) $\left.\mathrm{m}^{-2} \mathrm{~s}^{-1}\right]$, room temperature $\left(25^{\circ} \mathrm{C}\right), 60 \%$ relative humidity, all controlled by $C I R A S-3$. All the measurements were performed between 08:00 11:00 h on sunny days. The $P_{\mathrm{N}}-C_{\mathrm{i}}$ response curve was made according to Zhong et al. (2019a). The carboxylation efficiencies (CE) were computed on the base of initial slope of the $P_{\mathrm{N}}-C_{\mathrm{i}}$ response curves. The ribulose-1,5bisphosphate $(\mathrm{RuBP})$ maximal regenerating rates were the maximal $P_{\mathrm{N}}$ under a saturation $\mathrm{CO}_{2}$ concentration and saturation light intensity (Farquhar et al. 1980).

Chl fluorescence transient and $820-\mathrm{nm}$ reflection curve: The Chl fluorescence transients (OJIP curves) and 820-nm reflection curves were synchronously measured using an M-PEA instrument (Hansatech, King's Lynn, UK) according to Strasser et al. (2000). The leaves were cut into discs with $0.38 \mathrm{~cm}^{2}$ area; the discs were put into the centrifuge tube with different OBZ suspensions and then vacuum-treated for about $15 \mathrm{~min}$ to make sure that OBZ had entered leaf discs. The leaf discs were later darkadapted for about $30 \mathrm{~min}$. The OJIP and $820-\mathrm{nm}$ reflection curves of dark-adapted discs were detected by illuminating with 1 -s saturated light $\left[5,000 \mu \mathrm{mol}\right.$ (photon) $\left.\mathrm{m}^{-2} \mathrm{~s}^{-1}\right]$ provided by $M-P E A$.

Assay of PET: Chloroplast thylakoid membrane was extracted according to Zhong et al. (2019a), and the PET activities were measured using an Oxytherm oxygen electrode system (Hansatech, King's Lynn, UK). The activity of the whole PET chain was detected as $\mathrm{O}_{2}$ consumption with addition of $0.1 \mathrm{mM}$ methylviologen (MV) (Brandle et al. 1977). The PSII and PSI activities were detected according to Satoh et al. (1992) and De la Torre and Burkey (1990). The preparation of the reaction solution of control and OBZ treatment and the calculation of the inhibition ratio of electron transport by OBZ were performed according to Zhong et al. (2019a).

Statistical analysis: Least significant difference was computed with SPSS 11 program (SPSS Inc., Chicago, IL, USA). Standard error (SE) was computed with Excel (Microsoft, Redmond WA, USA).

\section{Results}

Plant growth: Irrigation with different OBZ concentrations obviously suppressed the growth of cucumber seedlings (Fig. 1A). The plant height, stem diameter, leaf area, and leaf Chl content were significantly lower in OBZ-treated cucumber plants than that in control plants. Treatment with different OBZ contents showed different inhibition extents on plants growth (Fig. 1).

Photosynthetic gas exchange: OBZ significantly inhibited the $P_{\mathrm{N}}$ and $g_{\mathrm{s}}$ of cucumber leaves under saturating light intensity, and these inhibitions intensified as the OBZ content increased. The $P_{\mathrm{N}}$ of cucumber leaves decreased by approximately $57 \%$ after the $45.6 \mathrm{mg} \mathrm{L}^{-1} \mathrm{OBZ}$ treatment. Although the $g_{\mathrm{s}}$ decreased in similar ways as the $P_{\mathrm{N}}$ did, the $C_{\mathrm{i}}$ did not change significantly with the increase in 

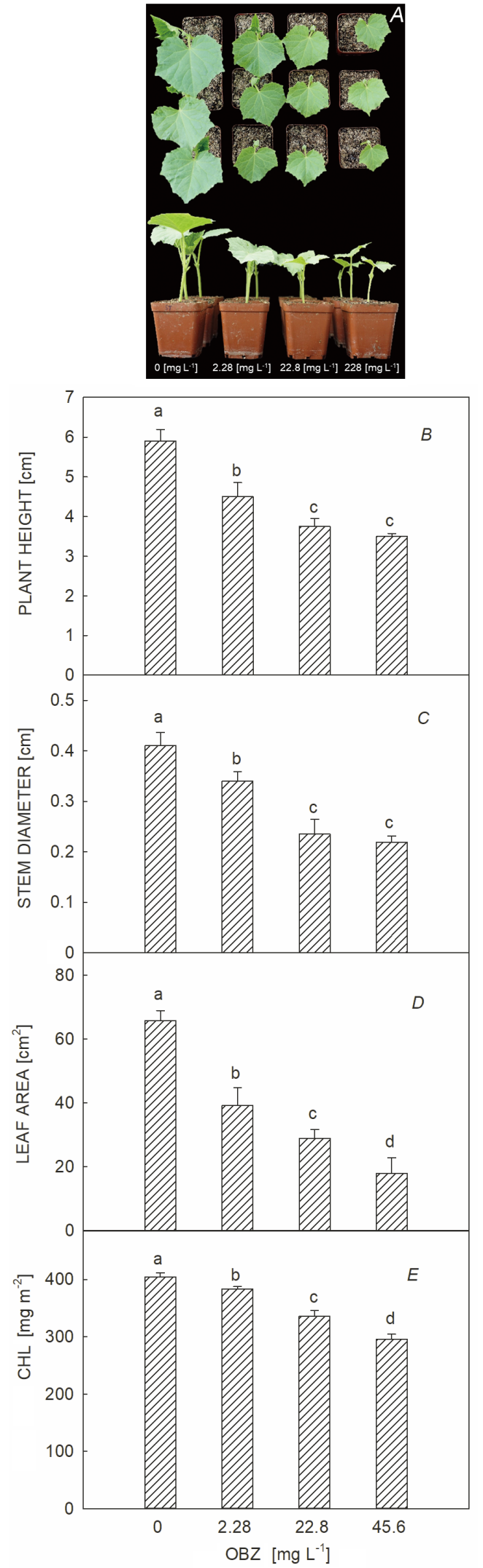

Fig. 1. The effects of 15-d treatments with different oxybenzone contents on the growth $(A)$, plant height $(B)$, stem diameter $(C)$, leaf area $(D)$, and chlorophyll content $(E)$ of cucumber.
OBZ content. To further analyze photosynthetic $\mathrm{CO}_{2}$ assimilation, the $\mathrm{CO}_{2}$-response curves were measured under saturating light intensity. Irrigation with OBZ decreased both the CE and RuBP maximum regeneration rate in cucumber leaves (Fig. 2).

Chl fluorescence transients and $820-\mathrm{nm}$ reflection curves: In order to investigate the mechanism of OBZ inhibition, we used suspensions with different OBZ content to treat leaf discs for a short period of time (45 $\mathrm{min})$. The OJIP curves and the normalized $820-\mathrm{nm}$ reflection curves were significantly affected by different-OBZ-content suspensions. The changes in the Chl fluorescence curve $\left(V_{t}\right)$ indicated that the inhibition ratio of PSII activity by OBZ increased with increasing OBZ content. The ' $\mathrm{J}$ ' point in the OJIP curve increased sharply with a rise of OBZ content (Fig. 3A). The 'J' point rose to the same height as the ' $\mathrm{P}$ ' point (Fig. $3 A$ ) when seedlings were treated with the $45.6 \mathrm{mg} \mathrm{L}^{-1}$ OBZ suspension. The $820-\mathrm{nm}$ reflection signals started declining soon after turning on the red light but after approximately $20 \mathrm{~ms}$, the decrease in 820-nm reflection was replaced by an increase in reflection. However, after treatment with suspensions of diverse OBZ content, the reversal of the $820-\mathrm{nm}$ reflection was inhibited, and the inhibition of the reversal increased with the increasing OBZ content. After treatment with the $45.6 \mathrm{mg} \mathrm{L}^{-1}$ OBZ suspension, the reversal was almost completely blocked (Fig. 3B), and it decreased further beyond this point.

PET of the chloroplasts: Based on measuring partial reactions of the full PET chain, OBZ was found to significantly inhibit the whole chain linear PET $\left(\mathrm{H}_{2} \mathrm{O} \rightarrow\right.$ MV) but not electron transfer through PSII or PSI alone, and the degree of inhibition increased with the increase in the OBZ content. The whole chain of PET was inhibited by approximately $92 \%$ by the $45.6 \mathrm{mg} \mathrm{L}^{-1} \mathrm{OBZ}$. However, neither the low OBZ content nor high OBZ content inhibited the activity of PSII $\left[\mathrm{H}_{2} \mathrm{O} \rightarrow p\right.$-benzoquinone $(p$-BQ) $]$ and PSI [2,6-dichlorophenolindophenol (DCPIP) $\rightarrow \mathrm{MV}]$ (Fig. 4).

\section{Discussion}

This study demonstrated that OBZ particles can be absorbed by plant roots even though the particles are insoluble in water. Suspensions with OBZ significantly restrained the $P_{\mathrm{N}}$ and growth of the plant (Figs. 1, 2). Although $P_{\mathrm{N}}$ and $g_{\mathrm{s}}$ decreased with increasing OBZ in a similar manner (Fig. 2A,B), no significant change in $C_{\mathrm{i}}$ was observed with increasing OBZ (Fig. $2 C$ ). According to the criteria proposed by Farquhar and Sharkey, a decrease in $P_{\mathrm{N}}$ is caused by stomatal limitation only when $g_{\mathrm{s}}$ and $C_{\mathrm{i}}$ decrease in a similar way, otherwise, such a decrease is caused by nonstomatal factors (Farquhar and Sharkey 1982). Therefore, the inhibition of photosynthesis in cucumber plants by OBZ was caused by nonstomatal factors, which include the diffusion resistance of $\mathrm{CO}_{2}$ in the mesophyll, light absorption and conversion, and PET and $\mathrm{CO}_{2}$ assimilation through the Calvin-Benson cycle. 

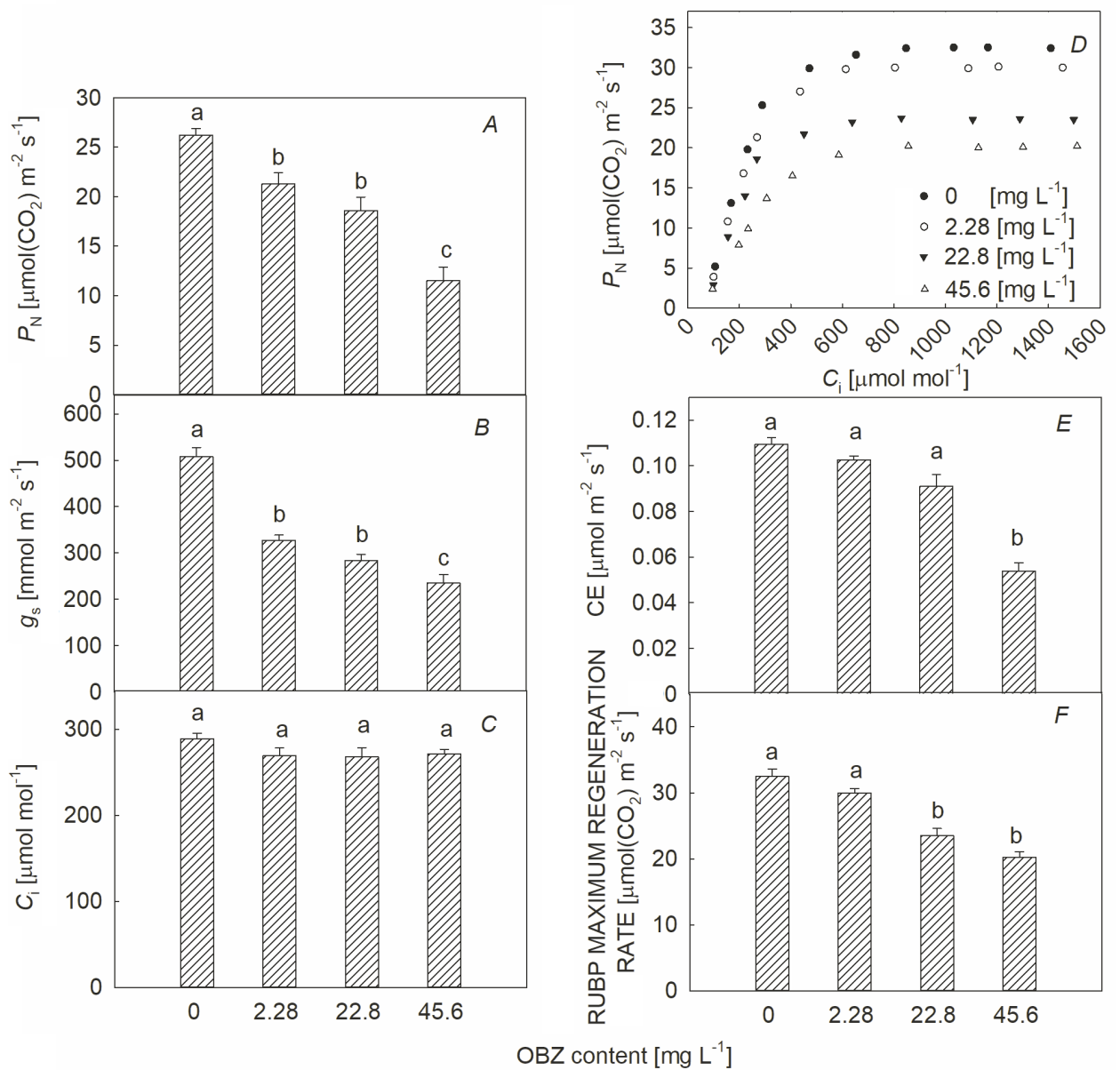

Fig. 2. The effects of $15-d$ treatments with different oxybenzone contents on the photosynthetic rate $\left(P_{\mathrm{N}}\right)(A)$, stomatal conductance $\left(g_{\mathrm{s}}\right)(B)$, intercellular $\mathrm{CO}_{2}$ concentration $\left(C_{\mathrm{i}}\right) \quad(C), \quad P_{\mathrm{N}}-C_{\mathrm{i}}$ response curve $(D)$, carboxylation efficiency $(\mathrm{CE})(E)$, and ribulose1,5-bisphosphate (RuBP) maximal regenerating rates $(F)$ in cucumber plants.

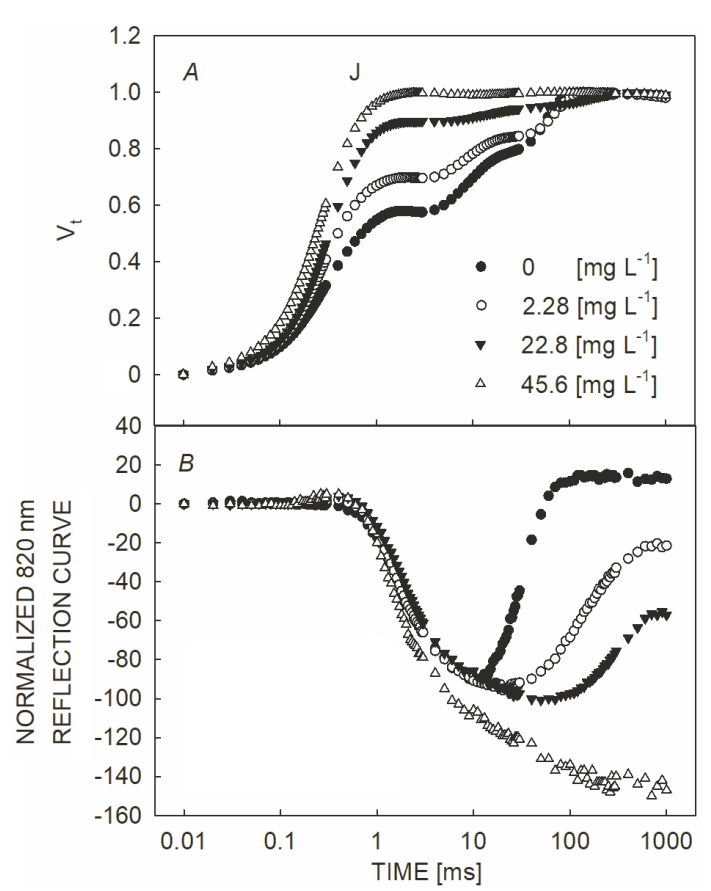

Fig. 3. The effects of 30-min treatments with different oxybenzone contents on the OJIP curves of leaf discs. $V_{t}$ curve [relative variable fluorescence at any time, $\mathrm{V}_{\mathrm{t}}=\left(\mathrm{F}_{\mathrm{t}}-\mathrm{F}_{0}\right) /$ $\left.\left(\mathrm{F}_{\mathrm{m}}-\mathrm{F}_{0}\right)\right](A)$ and normalized 820-nm reflection curve $(B)$.
To explore the mechanism of photosynthesis inhibition by OBZ, we analyzed the influence of OBZ on the Chl fluorescence transient, 820-nm reflection curve, and PET of PSI, PSII, and the whole linear electron transport chain as well as the $P_{\mathrm{N}}-C_{\mathrm{i}}$ response curve, CE and RuBP maximal regenerating rates of photosynthesis.

The Chl fluorescence transient has been widely used as a powerful tool to assess photosynthesis. The OJIP test established by Strasser (1978) has been used efficiently to reflect PSII activity (Jiang et al. 2006, Strasser and Stirbet 2001, Fan et al. 2014). A large number of studies have proven that an increase in the ' $\mathrm{J}$ ' point of the fluorescence transient indicates severe inhibition of the linear electron transport chain of photosynthesis from $\mathrm{Q}_{\mathrm{A}}$ to downstream electron receptors (Haldimann and Strasser 1999, Jia et al. 2010). When electron transport is completely blocked by 3-(3,4-dichlorophenyl)-1,1-dimethyl-urea (DCMU), which inhibits electron flow from $\mathrm{Q}_{\mathrm{A}}$ to the Cyt $b_{6} f$ complex, the ' $J$ ' point reaches a level as high as that of the 'P' point (Schansker et al. 2003). Therefore, the observation that the ' $\mathrm{J}$ ' point reached the ' $\mathrm{P}$ ' point after treatment with a $45.6 \mathrm{mg} \mathrm{L}^{-1} \mathrm{OBZ}$ suspension indicated that the treatment almost completely blocked the electron transport from $\mathrm{Q}_{\mathrm{A}}$ to the Cyt $b_{6} f$ complex.

In the past decade, the 820-nm absorption (Schansker et al. 2003) or reflection (Zhang et al. 2011) of leaves or chloroplasts has been used to reflect the redox activity 


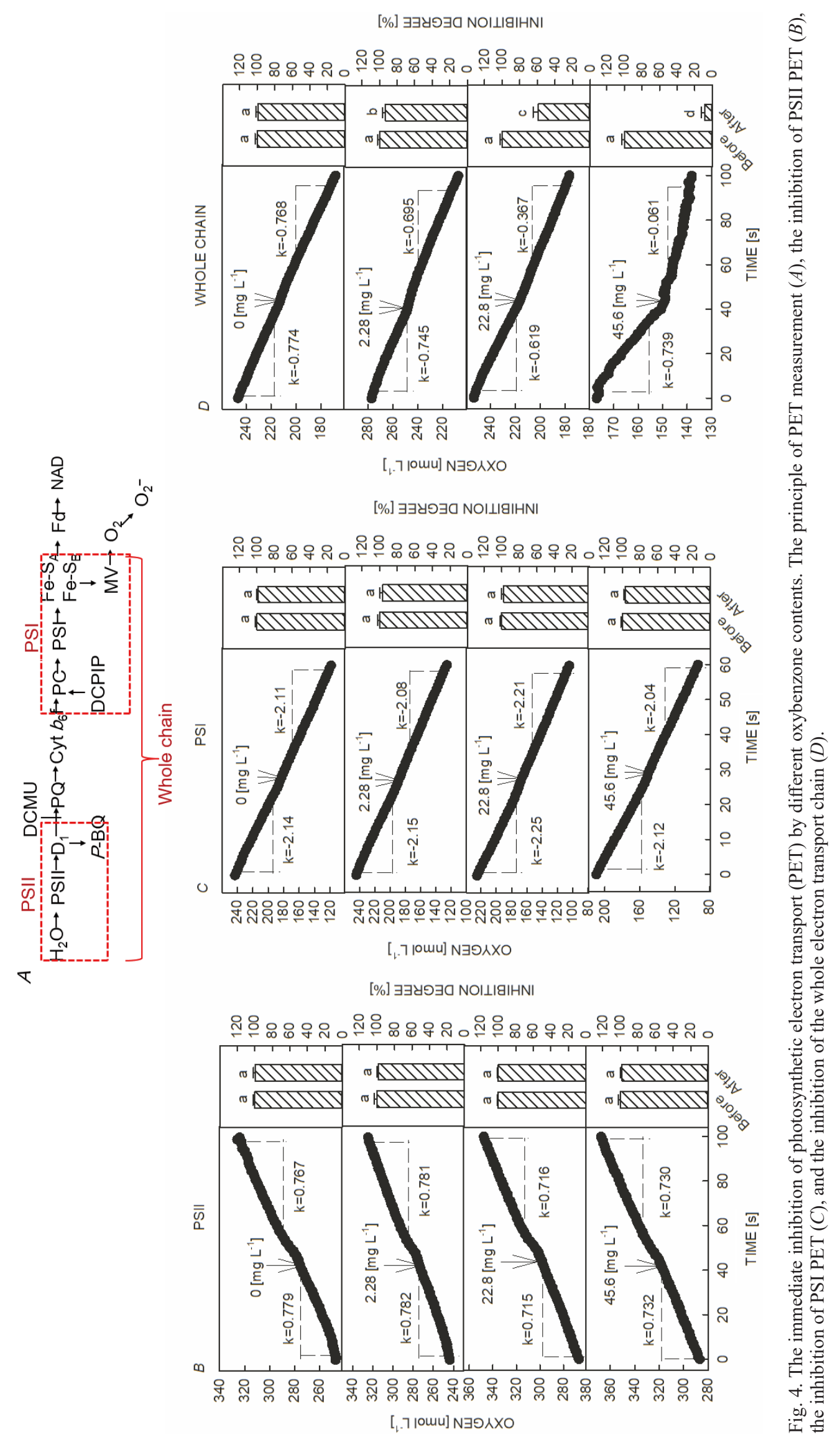


of PSI. A reversal of the decrease in $820-\mathrm{nm}$ reflection is caused by the arrival of electrons from PSII (Schansker et al. 2003). The inhibition of the reversal of $820-\mathrm{nm}$ reflection indicated that the electrons sent from PSII to reduce PSI were blocked. The fact that the reversal of $820-\mathrm{nm}$ reflection was almost completely blocked by the $45.6 \mathrm{mg} \mathrm{L}^{-1} \mathrm{OBZ}$ suspension further supported the assumption discussed above, specifically, that the electron transport from $\mathrm{Q}_{\mathrm{A}}$ to the Cyt $b_{6} f$ complex was almost completely blocked by $45.6 \mathrm{mg} \mathrm{L}^{-1} \mathrm{OBZ}$, so that PSI could not be reduced by electrons from PSII.

Analysis of the OJIP test and the changes in 820-nm reflection indicated that the inhibition of electron transport from $\mathrm{Q}_{\mathrm{A}}$ to the Cyt $b_{6} f$ complex was the principal reason for OBZ inhibition of photosynthesis. To further confirm this conclusion and narrow the hypothesized inhibition site, we used a more direct method of detecting $\mathrm{O}_{2}$ release (PSII) or $\mathrm{O}_{2}$ consumption (PSI and the whole linear chain) to evaluate the electron transport capacities of PSI, PSII, and the whole linear chain in chloroplasts with and without OBZ treatments.

OBZ did not inhibit the activity of PSII $\left(\mathrm{H}_{2} \mathrm{O} \rightarrow p\right.$-BQ) and PSI (DCPIP $\rightarrow$ MV) but significantly inhibited the whole linear electron transport chain $\left(\mathrm{H}_{2} \mathrm{O} \rightarrow \mathrm{MV}\right)$ (Fig. 4B-D), confirming that OBZ inhibited PET by inhibiting PQ and/or the Cyt $b_{6} f$ complex between PSI and PSII. Blocking PET in PQs and/or the Cyt $b_{6} f$ complex restricts the transport of the electrons generated by $\mathrm{H}_{2} \mathrm{O}$ photolysis in PSII to PSI, resulting in the accumulation of a large number of electrons in PSII reaction centers and, consequently, closure of these reaction centers. This hypothesis was supported by the sharp increase in the ' $\mathrm{J}$ ' point of the OJIP curve (Fig. 3A). The inhibition of PET leads to an increase in excess excitation energy, which inevitably causes overproduction of ROS (Zhang et al. 2014, Zhong et al. 2019a), further damaging the photosynthetic apparatus. We think this process underlies the indirect inhibition of photosynthesis by OBZ.

The inhibition of PET limits the synthesis of NADPH and ATP. ATP plays an important role in regulating the activity of Rubisco (EC 4.1.1.39), a key enzyme for $\mathrm{CO}_{2}$ assimilation. The actual Rubisco activities depend greatly on Rubisco-activase activity (Portis 2003). ATP is involved in the activation of Rubisco (Zielinski et al. 1989, Portis et al. 2008). The decrease in ATP synthesis caused by OBZ reduced Rubisco activation and CE. Furthermore, limiting the synthesis of NADPH and ATP directly inhibits $\mathrm{CO}_{2}$ reduction and RuBP regeneration through the Calvin-Benson cycle, which was supported here by the fact that the $\mathrm{CE}$ and $\mathrm{RuBP}$ maximal regenerating rates were significantly inhibited by OBZ treatment (Fig. 2D). Therefore, the decrease in $\mathrm{CO}_{2}$ assimilation was mainly due to the inhibition of PET by OBZ.

OBZ can enter rivers, lakes, swimming pools, groundwater, sewage, and irrigation water via human activities (Li et al. 2007, Zwiener et al. 2007, Goksøyr et al. 2009, Sánchez Rodríguez et al. 2015). Schneider and Lim (2019) found that these ultraviolet filters, including OBZ, are difficult to remove using conventional sewage treatment. The purpose of this study was to explore the
OBZ inhibition mechanism. In order to shorten treatment time and enhance the inhibition extent, we used higher OBZ content (over $2.28 \mathrm{mg} \mathrm{L}^{-1}$ ) in this study. In our previous study, we have proved that lower OBZ content such as $0.228 \mathrm{mg} \mathrm{L}^{-1}$ could obviously inhibit PET (Zhong et al. 2019a). Downs et al. (2016) have found that the detected OBZ content was $75 \mu \mathrm{g} \mathrm{L}^{-1}-1.395 \mathrm{mg} \mathrm{L}^{-1}$ in the Virgin Island, which is much higher than the content we have tested previously. In arid and semiarid regions, the reuse of treated wastewater for agricultural irrigation is increasing, and OBZ is thus more likely to be transferred to agricultural land (Wu et al. 2015). In our study, OBZ significantly affected the photosynthesis and growth of a higher plant through the irrigation water. Other scientists have also reported that biosolids in PPCPs are absorbed by plants via the roots and then accumulate continuously in plants (Wu et al. 2010, Cabrera-Peralta and Peña-Alvarez 2018). The results of our study can help us understand the limitation of agricultural production caused by OBZ and provide evidence to support limitations for the use of OBZ. The results also suggest the potential impact of other biosolids on agricultural production.

Our research demonstrated that the inhibition of photosynthesis in cucumber leaves by OBZ mainly resulted from the blocking of PET and that the possible PET inhibition sites were PQs and/or the Cyt $b_{6} f$ complex. To locate the precise inhibition site (PQs or Cyt $b_{6} f$ or both of them) needs more research. And it is worth clarifying the inhibition mechanism of PQ and/or Cyt $b_{6} f$ complex

Conclusions: Our research demonstrated that OBZ could be absorbed by plant roots and significantly inhibited photosynthesis and growth of cucumber seedlings. OBZ directly blocked linear PET by inhibiting PQs and/or Cyt $b_{6} f$ complex, restricting the reduction of PSI reaction center. The inhibition of PET can cause accumulation of ROS and lack of assimilatory power (ATP and NADPH), which would damage cell membrane and photosynthetic apparatus, and restrict $\mathrm{CO}_{2}$ assimilation via inhibiting the Calvin-Benson cycle. Therefore, it is important to limit the use of sunscreens containing OBZ to protect aquatic and terrestrial ecosystems and ensure the safety of agricultural production.

\section{References}

Agüera A., Bueno M.J.M., Fernández-Alba A.R.: New trends in the analytical determination of emerging contaminants and their transformation products in environmental waters. Environ. Sci. Pollut. R. 20: 3496-3515, 2013.

Aguirre A., Izu R., Gardeazabal J. et al.: Allergic contact cheilitis from a lipstick containing oxybenzone. - Contact Dermatitis 27: 267-267, 1992.

Baker L.A., Horbury M.D., Greenough S.E. et al.: Probing the ultrafast energy dissipation mechanism of the sunscreen oxybenzone after UVA irradiation. - J. Phys. Chem. Lett. 6: 1363-1368, 2015.

Barón E., Gago-Ferrero P., Gorga M. et al:: Occurrence of hydrophobic organic pollutants (BFRs and UV-filters) in sediments from South America. - Chemosphere 92: 309-316, 2013. 
Brandle J.R., Campbell W.F., Sisson W.B., Caldwell M.M.: Net photosynthesis, electron transport capacity, and ultrastructure of Pisum sativum L. Exposed to ultraviolet-B radiation. Plant Physiol. 60: 165-169, 1977.

Cabrera-Peralta J., Peña-Alvarez A.: Simple method for the determination of personal care product ingredients in lettuce by ultrasound-assisted extraction combined with solid-phase microextraction followed by GC-MS. - J. Sep. Sci. 41: 22532260, 2018.

Chen F., Huber C., Schröder P.: Fate of the sunscreen compound oxybenzone in Cyperus alternifolius based hydroponic culture: Uptake, biotransformation and phytotoxicity. Chemosphere 182: 638-646, 2017.

Chen F., Schnick S., Schröder P.: Concentration effects of the UV filter oxybenzone in Cyperus alternifolius: Assessment of tolerance by stress-related response. - Environ. Sci. Pollut. R. 25: 16080-16090, 2018.

De la Torre W.R., Burkey K.O.: Acclimation of barley to changes in light intensity: Photosynthetic electron transport activity and components. - Photosynth. Res. 24: 127-136, 1990.

Downs C.A., Kramarsky-Winter E., Segal R. et al:: Toxicopathological effects of the sunscreen UV filter, oxybenzone (benzophenone-3), on coral planulae and cultured primary cells and its environmental contamination in Hawaii and the U.S. Virgin Islands. - Arch. Environ. Con. Tox. 70: 265-288, 2016.

Emonet S., Pasche-Koo F., Perin-Minisini M.J., Hauser C.: Anaphylaxis to oxybenzone, a frequent constituent of sunscreens. - J. Allergy Clin. Immun. 107: 556-557, 2001.

Fan X., Zhang Z., Gao H. et al.: Photoinhibition-like damage to the photosynthetic apparatus in plant leaves induced by submergence treatment in the dark. - PLoS ONE 9: e89067, 2014.

Farquhar G.D., Sharkey T.D.: Stomatal conductance and photosynthesis. - Annu. Rev. Plant Biol. 33: 317-345, 1982.

Farquhar G.D., von Caemmerer S., Berry J.A.: A biochemical model of photosynthetic $\mathrm{CO}_{2}$ assimilation in leaves of $\mathrm{C}_{3}$ species. - Planta 149: 78-90, 1980.

Goksøyr A., Tollefsen K.E., Grung M. et al.: Balsa raft crossing the pacific finds low contaminant levels. - Environ. Sci. Technol. 43: 4783-4790, 2009.

Haldimann P., Strasser R.J.: Effects of anaerobiosis as probed by the polyphasic chlorophyll $a$ fluorescence rise kinetic in pea (Pisum sativum L.). - Photosynth. Res. 62: 67-83, 1999.

Jia Y.J., Cheng D.D., Wang W.B. et al.: Different enhancement of senescence induced by metabolic products of Alternaria alternata in tobacco leaves of different ages. - Physiol. Plantarum 138: 164-175, 2010.

Jiang C.D., Shi L., Gao H.Y. et al.: Development of photosystems 2 and 1 during leaf growth in grapevine seedlings probed by chlorophyll $a$ fluorescence transient and $820 \mathrm{~nm}$ transmission in vivo. - Photosynthetica 44: 454-463, 2006.

Kasichayanula S., House J.D., Wang T., Gu X.: Percutaneous characterization of the insect repellent DEET and the sunscreen oxybenzone from topical skin application. Toxicol. Appl. Pharm. 223: 187-194, 2007.

Lenique P., Machet L., Vaillant L. et al.: Contact and photocontact allergy to oxybenzone. - Contact Dermatitis 26: 177-181, 1992.

Li W., Ma Y., Guo C. et al.: Occurrence and behavior of four of the most used sunscreen UV filters in a wastewater reclamation plant. - Water. Res. 41: 3506-3512, 2007.

Mao F., He Y., Kushmaro A., Gin K.Y.: Effects of benzophenone-3 on the green alga Chlamydomonas reinhardtii and the cyanobacterium Microcystis aeruginosa. - Aquat. Toxicol. 193: $1-8,2017$.
Porra R.J.: The chequered history of the development and use of simultaneous equations for the accurate determination of chlorophylls $a$ and $b$. - Photosynth. Res. 73: 149-156, 2002.

Portis Jr. A.R., Li C., Wang D. et al.: Regulation of Rubisco activase and its interaction with Rubisco. - J. Exp. Bot. 59: 1597-1604, 2008.

Portis Jr. A.R.: Rubisco activase-Rubisco's catalytic chaperone.Photosynth. Res. 75: 11-27, 2003.

Rodil R., Quintana J.B., Concha-Graña E. et al.: Emerging pollutants in sewage, surface and drinking water in Galicia (NW Spain). - Chemosphere 86: 1040-1049, 2012.

Sánchez Rodríguez A., Rodrigo Sanz M., Betancort Rodríguez J.: Occurrence of eight UV filters in beaches of Gran Canaria (Canary Islands). An approach to environmental risk assessment. - Chemosphere 131: 85-90, 2015.

Satoh K., Koike H., Ichimura T., Katoh S.: Binding affinities of benzoquinones to the $\mathrm{Q}_{\mathrm{B}}$ site of photosystem II in Synechococcus oxygen-evolving preparation. - BBABioenergetics 1102: 45-52, 1992.

Schansker G., Srivastava A., Strasser R.J.: Characterization of the $820-\mathrm{nm}$ transmission signal paralleling the chlorophyll $a$ fluorescence rise (OJIP) in pea leaves. - Funct. Plant Biol. 30: 785-796, 2003.

Schneider S.L., Lim H.W.: Review of environmental effects of oxybenzone and other sunscreen active ingredients. - J. Am. Acad. Dermatol. 80: 266-271, 2019.

Strasser R.J.: The grouping model of plant photosynthesis. In: Akoyunoglou G., Argyroudi-Akoyunoglou J.H. (ed.): Chloroplast Development. Pp. 513-524. Elsevier/NorthHolland Biomedical Press, Amsterdam 1978.

Strasser R.J., Srivastava A., Tsimilli-Michael M.: The fluorescence transient as a tool to characterize and screen photosynthetic samples. - In: Yunus M., Pathre U., Mohanty P. (ed.): Probing Photosynthesis: Mechanism, Regulation and Adaptation. Pp. 445-483. CRC Press, New York 2000.

Strasser R.J., Stirbet A.D.: Estimation of the energetic connectivity of PSII centres in plants using the fluorescence rise O-J-I-P: Fitting of experimental data to three different PSII models. - Math. Comput. Simulat. 56: 451-462, 2001.

Tashiro Y., Kameda Y.: Concentration of organic sun-blocking agents in seawater of beaches and coral reefs of Okinawa Island, Japan. - Mar. Pollut. Bull. 77: 333-340, 2013.

Vione D., Caringella R., De Laurentiis E. et al.: Phototransformation of the sunlight filter benzophenone-3 (2-hydroxy-4methoxybenzophenone) under conditions relevant to surface waters. - Sci. Total Environ. 463-464: 243-251, 2013.

Wu C., Spongberg A.L., Witter J.D. et al.: Uptake of pharma“ceutical and personal care products by soybean plants from soils applied with biosolids and irrigated with contaminated water. - Environ. Sci. Technol. 44: 6157-6161, 2010.

Wu X., Dodgen L.K., Conkle J.L., Gan J.: Plant uptake of pharmaceutical and personal care products from recycled water and biosolids: A review. - Sci. Total Environ. 536: 655666, 2015.

Zhang Z., Jia Y., Gao H. et al.: Characterization of PSI recovery after chilling-induced photoinhibition in cucumber (Cucumis sativus L.) leaves. - Planta 234: 883-889, 2011.

Zhang Z.S., Yang C., Gao H.Y. et al.: The higher sensitivity of PSI to ROS results in lower chilling-light tolerance of photosystems in young leaves of cucumber. - J. Photoch. Photobio. B 137: 127-134, 2014.

Zhong X., Che X., Zhang Z. et al.: Slower development of PSI activity limits photosynthesis during Euonymus japonicus leaf development. - Plant. Physiol. Bioch. 136: 13-21, 2019 b.

Zhong X., Li Y., Che X. et al.: Significant inhibition of photosynthesis and respiration in leaves of Cucumis sativus 
L. by oxybenzone, an active ingredient in sunscreen. Chemosphere 219: 456-462, 2019a.

Zielinski R.E., Werneke J.M., Jenkins M.E.: Coordinate expression of Rubisco activase and Rubisco during barley leaf cell development. - Plant. Physiol. 90: 516-521, 1989.

Zwiener C., Richardson S.D., De Marini D.M. et al.: Drowning in disinfection byproducts? Assessing swimming pool water. Environ. Sci. Technol. 41: 363-372, 2007.

(C) The authors. This is an open access article distributed under the terms of the Creative Commons BY-NC-ND Licence. 